\title{
More palliative care specialists is not enough
}

I n light of Quebec legalizing euthanasia and Canada's aging population, the quality and availability of palliative care is emerging as a crucial issue, say experts in the area. But while the conversation has often centred on the number of palliative care specialists, that's only part of the solution.

By international standards, Canada has fewer doctors specializing in palliative care than some comparable countries. In 2012, about 200 palliative care physicians worked either part- or fulltime in Canada, comprising just $0.28 \%$ of all Canadian doctors. By comparison, the latest available figures show that the US had $0.52 \%$ and Australia had $0.38 \%$.

How many specialists in palliative care does Canada need? The Canadian Society of Palliative Care Physicians and others are currently conducting a survey aimed, in part, at finding out. But the society's president, Dr. Susan MacDonald, says that although specialists are essential for complex cases and as consultants and educators, often trained primary care providers can do the job.

"Not everyone is going to need to see specialized teams," agrees Leanne Clarke at the Canadian Hospice Palliative Care Association. Clarke runs The Way Forward initiative, which is facilitating a national conversation about integrating a palliative approach in primary care. This involves integrating skills and tools for palliative care into primary care, including outpatient offices, home care organizations and long-term care facilities.

"Many people who have progressive life-limiting illnesses that aren't medically complex or people who are aging and frail don't need to be in specialized and tertiary centres," she says.

The authors of a 2013 commentary in Canadian Family Physician take issue with the "widely cited" claim that only $16 \%-30 \%$ of those who need palliative care receive it. "The fallacy in this claim is the implication that all Canadians approaching the end of life should be cared for by specialist palliative care teams," state the authors.

"We can fall into the trap of thinking that more specialty care physicians are the solution to the problem," says

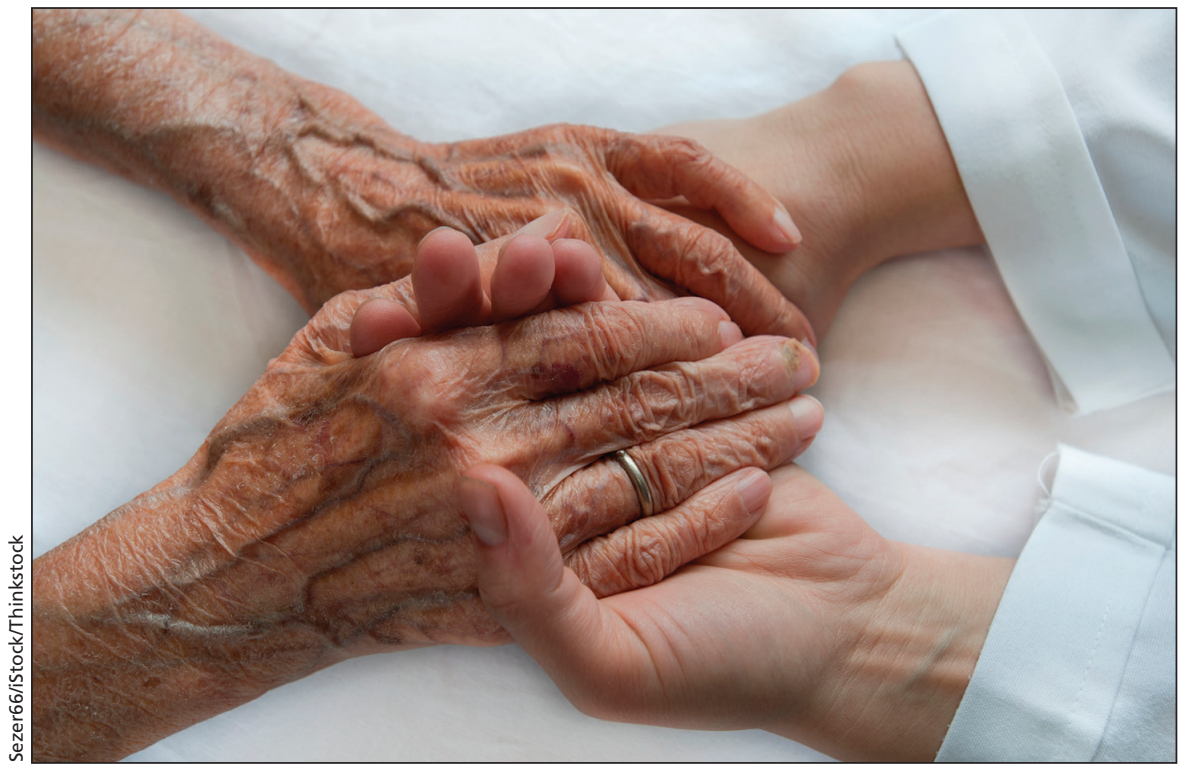

In addition to boosting the number of palliative care specialists, primary care providers need more training.

co-author Dr. Joshua Shadd. "They are certainly an important piece, but another piece is education for all health care providers, including family physicians."

Shadd, an assistant professor at Schulich School of Medicine and Dentistry in London, Ontario, says the ideal model involves palliative care physicians as consultants to primary care providers.

The problem, says MacDonald, is that most primary health care doctors are not adequately trained to provide palliative care for patients. "Something like 10 out of 17 medical schools have only 10 hours of palliative care training. How can you expect them, with such basic training, to understand the stages of dying and how to counsel families?"

Both MacDonald and Shadd's views are echoed in a 2011 report by the Quality Hospice Palliative Care Coalition of Ontario, which found a shortage of health care professionals with training in palliative care, grief and bereavement support, including "a lack of expertise and specialized resources for primary care settings."

Shadd says all health care providers should possess basic palliative care knowledge pertinent to their discipline. "It's not just physicians... . The nurses, personal support workers, social workers and all of the people supporting that person need to have that education."

He says an important step is to understand the quality of the current palliative care, who delivers that care and what the population needs.

In November 2014, the Canadian Medical Association partnered with the College of Family Physicians of Canada, the Royal College of Physicians and Surgeons of Canada, and the Technology Evaluation in the Elderly Network to obtain a snapshot of the palliative medicine workforce today. They emailed a survey to members of the two colleges and to members of the Canadian Society of Palliative Care Physicians who didn't belong to either college. The results will be available in May 2015.

These are data that the Ontario government says it needs. "Currently, the ministry lacks information on the palliative-care services available, their costs, the patient need for these services, or what mix of services would best meet patient needs in a cost-effective manner," states the Annual Report of the Office of the Auditor General of Ontario. The underlying reason for the difficulty in getting data, according to that report, is the patchwork of initiatives in palliative care. - Dane Wanniarachige, CMAJ 